\title{
The social context of ageing and intergenerational relationships in Chinese families
}

Stevi Jackson ${ }^{1}$ and Jieyu Liü ${ }^{2 *}$

* Correspondence:
jieyuliu@soas.ac.uk
${ }^{2}$ SOAS China Institute, SOAS
University of London, London
WC1H OXG, UK
Full list of author information is
available at the end of the article

available at the end of the article
Population ageing is a global issue, primarily in richer and developed countries, and raises questions about the place of elders in society, their quality of life, and care for those who can no longer care for themselves, as well as the wider socio-economic consequences of population imbalance. China is a very specific case as the demographic transition from a youthful society to an ageing one took place at an earlier stage of economic development than in most richer countries and has happened much faster. This is partly a consequence of the imposition of the one child-policy, rather than a gradual decrease in family size through couples choosing to have fewer children, but also reflects a particularly dramatic increase in life expectancy over the last half century, from around 43 in the 1960 s to 76 in $2014 .^{1}$

The one-child policy was introduced in 1979, after which couples were only allowed to give birth to one child. In urban areas, this policy was strictly implemented through the work unit (danwei) (Liu 2007). Since the work unit was the most important (sometimes only) source of livelihood for urban residents prior to the 1990s, urban couples had to comply with this social control, for which they were compensated with a pension from their work unit (Liu 2007). But in rural areas, since farmers were largely dependent on their children to assist with farm work and old age support, there was considerable resistance. As a result, from the mid-1980s, the state modified the policy for rural couples so that if their first child was a girl they were allowed another child (Hesketh et al. 2005). More recently, the policy has been relaxed for urban couples as well, in part because of concerns about China's ageing society. In 2015, the number of people in China who were 60 and over had reached 222 million (16\% of the population, China's Ministry of Civil Affairs 2016). By 2050, this number is expected to exceed 400 million (35\% of the population). What makes China different, and the challenges more acute, is the sheer number of people (almost $20 \%$ of the world's population), the stage of economic development, and the relatively low GNP. While state policy has played a critical part in contributing to super ageing in China (Joseph and Phillips 1999), the state is reluctant to provide comprehensive welfare and pension support for all its citizens, especially rural residents due to the long institutionalized urban-rural divide. As a result, families remain the main source of welfare and support in contemporary China (Shang and Wu 2011).

Chinese families bear the brunt of this demographic challenge in a wider context of extremely rapid socio-economic transformations since the inception of the economic

(c) The Author(s). 2017 Open Access This article is distributed under the terms of the Creative Commons Attribution 4.0 International License (http://creativecommons.org/licenses/by/4.0/), which permits unrestricted use, distribution, and reproduction in any medium, provided you give appropriate credit to the original author(s) and the source, provide a link to the Creative Commons license, and indicate if changes were made. 
reform in the 1980s. The gap in life experience and expectations between generations can, as a result, be very wide. The younger generation in urban cities, unlike their parents whose education suffered during the Cultural Revolution, tend to have higher educational qualifications, and many are becoming white-collar professionals; while still deeply embedded in intergenerational ties, they develop more individualistic ideas focusing upon self-development (Liu 2016a). With China's opening up and the easing of restrictions on rural to urban mobility, the younger generation tend to be more mobile, whether it be inter-city migration or overseas migration in urban families or large-scale rural to urban migration in rural families. This geographical mobility features, in different ways and to different degrees, in all the articles in this special issue. Not only does mobility increase physical distances between family members, but also potentially cultural distance as young people develop new lifestyles separate from their parents. As some go abroad for education or work, and increasing numbers of foreigners live and work in China, young people may be exposed to different ideas about family life. Cross-national marriages are also an outcome of these new patterns of mobility, which further complicate the challenges facing Chinese families (see Nehring and Wang).

This background creates new challenges to old ideals of filial piety, which have long been the guiding principle of relations between ageing parents and adult children. Moreover, as a result of the one child policy, many younger adults born after 1980 have no support from siblings in managing provision for their parents in old age, thus increasing their potential burden. This special issue makes a timely contribution to understanding some of the consequences of population ageing for intergenerational relations in China through qualitative research on family strategies and practices. The papers included do not focus on the obvious problems of ageing (or the elderly as a problem), but instead highlight subtler, but nonetheless important changes taking place in Chinese families in terms of renegotiating intergenerational obligations and planning to manage care and support in the context of a rapidly ageing society, new family configurations and insufficient welfare support from the state.

The nature of the intergenerational contract has evolved from a model of submission embodied in traditional filial piety to a diversified model. For example, by analyzing families split between China and the UK, Tu reveals that adult children in the UK and their parents in China are embedded in a close two-way transfer model despite the geographic distance: rather than relying upon their children, these parents were important source of material support to their children; one-child migrants tended to compensate for the lack of material/practical care by providing long distance emotional care to their parents. Focusing upon the impact of rural to urban migration upon rural households, Liu indicates that care circulates between different family members, in different locations, to differing degrees, over the life course, going beyond a unidirectional flow, or two-way transfer.

The characteristics of the intergenerational contract seems also to be undergoing modification. Although traditional filial piety emphasizes all-round support from adult children to their parents, existing studies have found that material support was the main and sometimes only old age support actually provided (Miller 2004). While acknowledging material provision in old age remains critical in the context of insufficient state welfare, other aspects of intergenerational relations are gradually becoming important. For example, among the transnational families in the UK, Tu reveals that 
emotional support is the main way in which adult children reciprocate parents' material support. Nehring and Wang argue that among the Chinese transnational families in Beijing, the family becomes an individualized intimate space, within which meanings of family, filial piety, and marriage cannot be taken for granted and require an ongoing process of reflexive negotiation to become and remain mutually acceptable to both foreign spouses and the Chinese families into which they have married. Liu demonstrates how the delivery of good quality care from adult migrating children to parents depends upon a number of factors, one of which being how intimate parents are with their children. Zhang's data indicates varied forms of care and material support depending on the circumstances of both parents and adult children as well as the specific material and emotional needs of the former and resources (of both time and money) of the latter, sometimes resulting in complex intrafamilial negotiations and arrangements involving wider kin. Whatever the living arrangements and economic situation of these, the northern Chinese research families, the ideal of filial obligation was retained, even though it was practiced in diverse, and often new, ways.

The structure of Chinese families is changing. Unlike the traditional ideal under which several generations lived under one roof and shared one stove, separation has become a common and accepted feature of contemporary Chinese family life. As Zhang, $\mathrm{Liu}$, and $\mathrm{Tu}$ all found, however, adult children living apart from their parents does not lead to the erosion of filial piety. However, the consequences of migration for the practice of filial piety are variable. Because of the different economic background of the families in Liu's rural sample and Tu's more affluent urban residents, how they were adapting to the separation and the consequences of ageing differed tremendously. Such differences also emerge within Zhang's study, which includes some wealthier families where ageing parents do not need economic support, but also those on modest income and those with parents in rural areas who need economic support from their children to survive.

Another key feature of this special issue is that all the studies are qualitative in focus. While statistical analyses of demographic change and its consequences are important in sketching out broad contours of the social landscape, qualitative studies such as those presented here add texture and detail, enabling us to understand the experiences and interpretations of the people who have gone through these social changes and population challenges. For example, Zhang reveals the nuanced ways in which displaying intimacy plays a role in maintaining intergenerational bonds, the importance of acts of care that give face to elders and therefore contribute to their emotional wellbeing-as well as adult children themselves gaining face, or avoiding its loss, through appropriate displays of filial piety. Liu points out that existing surveys only used the term zhaogu (care for) which cannot capture the quality of care relationships. The care about element is more neatly captured through ethnographic observations and interviews where individuals are enabled to discuss their feelings for their elders and the dilemmas they face in day to day life. The complexity of families that include non-Chinese members, as discussed by Nehring and Wang, highlights the different cultural norms of filial expectations and practices which pose interesting and unpredictable challenges unlikely to be revealed by survey data.

These papers also offer some conceptual advances and interventions into ongoing sociological debates. This is perhaps most obvious in Zhang's paper where she argues 
for bringing western sociological concepts such as practices of intimacy and displaying family into dialogue with Chinese concepts of xiao and mianzi, thus following in the footsteps of others who have suggested that Chinese concepts may have broader sociological purchase (e.g., Qi 2014). All the papers, however, address the larger debates on processes of individualization and detraditionalization and their contested consequences for intimate relationships, which have been the subject of much debate in both western and Asian contexts in recent decades (Beck and Beck-Gernsheim 2002; Gross 2005; Heaphy 2007; Yan 2009; Chang and Song 2010; Jamieson 2011). All the papers indicate that it is unwise to think of these processes as either linear or universal. It is clear that in Chinese society, as elsewhere, relationships with intimate others continue to be important in how individuals see themselves and their social obligations (see also Liu 2016b) ${ }^{2}$; and, rather than assuming a simple move away from traditional precepts, we should think perhaps of the ways in which traditions are reshaped and renegotiated to meet new circumstances and the importance of material constraints for such modifications (Jackson et al. 2013).

The papers in this special issue all address, in various ways, how members of modern Chinese families are negotiating changes in relationships between generations and the opportunities and constraints that face them. So what conclusions can we reach in this special issue? We found that there is continued importance of filial piety but it has been reconstructed and reworked under new conditions. Chinese families now look very different from those of 1949. Families have grown smaller with the decline in intergenerational co-residence and the impact of the one-child policy, but children and parents maintain close ties and exchanges of material, instrumental, and emotional support. The Confucian family ideology which undergirded relations between elders and the young, husbands and wives, has been shaken so that intergenerational relations are more often based on mutuality than on obedience, but the practical need for family care to compensate for inadequate social welfare ensures that filial piety is still expressed, albeit in a modified form. We also need to take account of the geographical and economic constraints facing families when care for ill or disabled elders becomes necessary. As Zhang's study indicates, those who are relatively affluent can consider the possibilities of hiring domestic help or paying for a private care home-even if the latter proves problematic in terms of traditional filial norms. For poorer couples juggling the multiple demands of maintaining an adequate income, caring for their child or children and elders, a crisis in the life circumstances of their parents could prove close to unmanageable (see also Liu's rural sample). Since traditional family practices have changed, there is an urgent need for the state policy-makers to catch up with reality and take into consideration the diversified family forms and new family practices rather than take the Chinese family for granted and assume that families can always provide care for ageing relatives.

\section{Endnotes}

${ }^{1}$ Statistics are for life expectancy at birth as reported by the World Bank. Available at http://data.worldbank.org/indicator/SP.DYN.LE00.IN?locations $=\mathrm{CN}$, Accessed 27/ $11 / 2016$.

${ }^{2}$ Liu (2016b) examines how the sociological concept of intimacy could be utilized in studying the relationship between adult children and aging parents in China, an area 
which has been predominantly located in an obligatory framework (embodied in filial piety [xiao] and its newly modified form intergenerational contract). Liu reveals that the complex relations between intimacy and obligation are the product of local socioeconomic circumstances and gender norms.

Authors' contributions

Both authors read and approved the final manuscript.

\section{Competing interests}

The authors declare that they have no competing interests.

\section{Author details}

${ }^{1}$ Centre for Women's Studies, University of York, York YO10 5DD, UK. ${ }^{2}$ SOAS China Institute, SOAS University of London London WC1H OXG, UK.

Received: 8 December 2016 Accepted: 8 December 2016

Published online: 06 January 2017

\section{References}

Beck, U., and E. Beck-Gernsheim. 2002. Individualization: institutionalized individualism and its social and political consequences. London: Sage.

Chang, K.-S., and M.-Y. Song. 2010. The stranded individualizer under compressed modernity: South Korean women in individualization without individualism. British Journal of Sociology 61(3): 539-564.

China's Ministry of Civil Affairs. 2016. 2015 Social Services Development Statistical Report. http://www.mca.gov.cn/article/ sj/tjgb/201607/20160700001136.shtml. Accessed 1/10/2016. [in Chinese].

Gross, N. 2005. The detraditionalization of intimacy reconsidered'. Sociological Theory 23(3): 268-311.

Heaphy, Brian. 2007. Late modernity and social change: reconstructing social and personal life. London: Routledge.

Hesketh, Therese, Li Lu, and Weixing Zhu. 2005. The effect of China's one-child family policy after 25 years'. The New England of Journal of Medicine. 353: 1171-1176.

Jackson, S., P.S.Y. Ho, and J.N. Na. 2013. Reshaping tradition? Women negotiating the boundaries of tradition and modernity in Hong Kong and British families'. The Sociological Review 61(4): 667-688.

Joseph, A.E., and D.R. Phillips. 1999. Ageing in rural China: impacts of increasing diversity in family and community resources'. Journal of Cross-Cultural Gerontology 14: 153.

Liu, Jieyu. 2007. Gender and work in urban China: women workers of the unlucky generation. London: Routledge.

Liu, Jieyu. 2016a. Gender, Power and Sexuality in Chinese Companies: Beauties at Work. London: Palgrave MacMillan.

Liu, Jieyu. 2016b. Intimacy and intergenerational relations in rural China, Sociology, 1-19. doi:10.1177/0038038516639505.

Jamieson, Lynn. 2011. 'Intimacy as a concept: explaining social change in the context of globalization or another form of ethnocentrism?' Sociological Research Online, 16 (4), http://www.socresonline.org.uk/16/4/15.html. Accessed 1 Nov 2016.

Miller, E.T. 2004. Filial daughters, filial sons: comparisons from north rural China. In Filial Piety, ed. C. Ikels, 34-52. Stanford: Stanford University Press.

Qi, Xiaoying. 2014. Globalized knowledge flows and Chinese social theory. London: Routledge.

Shang, X.Y., and X.M. Wu. 2011. The care regime in China. Journal of Comparative Social Welfare 27(2): 123-131.

Yan, Yunxiang. 2009. The Individualization of Chinese Society. Oxford: Berg.

\section{Submit your manuscript to a SpringerOpen ${ }^{\circ}$ journal and benefit from:}

- Convenient online submission

- Rigorous peer review

- Immediate publication on acceptance

- Open access: articles freely available online

- High visibility within the field

- Retaining the copyright to your article 